\title{
Differential impact of Holder and High Temperature Short Time pasteurization on the dynamic in vitro digestion of human milk in a preterm newborn model
}

\author{
Stefano Nebbia ${ }^{\mathrm{a}, \mathrm{b}}$, Marzia Giribaldi ${ }^{\mathrm{c}}$, Laura Cavallarin ${ }^{\mathrm{b}, *}$, Enrico Bertino ${ }^{\mathrm{d}}$, Alessandra Coscia ${ }^{\mathrm{d}}$, \\ Valérie Briard-Bion $^{\mathrm{a}}$, Jordane Ossemond ${ }^{\mathrm{a}}$, Gwénaële Henry ${ }^{\mathrm{a}}$, Olivia Ménard ${ }^{\mathrm{a}}$, Didier Dupont ${ }^{\mathrm{a}}$, \\ Amélie Deglaire ${ }^{\mathrm{a}}$
}

${ }^{\text {a }}$ STLO, INRAE, Institut Agro, 35042, Rennes, France

b Institute of the Science of Food Production - National Research Council, Largo Braccini 2, 10095 Grugliasco (TO), Italy

${ }^{\mathrm{c}}$ CREA Research Centre for Engineering and Agro-Food Processing, Strada delle cacce 73, Turin, Italy

${ }^{\mathrm{d}}$ Neonatal Unit, University of Turin, City of Health and Science of Turin, via Ventimiglia 3, 10126 Turin, Italy

\section{A R T I C L E I N F O}

\section{Keywords:}

Donor milk

Pasteurization

HTST

Preterm

Digestomic

Milk fat globule membrane proteins

\begin{abstract}
A B S T R A C T
The high-temperature short-time (HTST, $72{ }^{\circ} \mathrm{C}, 15 \mathrm{~s}$ ) pasteurization of human milk (HM) has been proposed as an alternative to the Holder method (HoP, $\left.62.5^{\circ} \mathrm{C}, 30 \mathrm{~min}\right)$, to increase the preservation of bioactive compounds. We have investigated the impact of HTST and HoP pasteurization on the gastrointestinal kinetics of human milk, using a dynamic in vitro system in a preterm newborn model. An increased protein aggregation on the surface of fat globules following pasteurization, albeit to a lesser extent in HTST than in HoP, was observed. Despite relevant differences in the undigested milk samples, both pasteurization methods led to similar proteolytic patterns, while raw HM presented a higher native lactoferrin content throughout digestion. The slightly decreased amino acid release following HoP, with respect to HTST and raw HM, indicated that peptidomic analysis, which is currently underway, might provide interesting insights on the differential digestive kinetics of differently pasteurized HM.
\end{abstract}

\section{Introduction}

A mother's own milk (MOM) is considered the best feeding choice for all infants, due to its capacity to adapt to the infant's needs, thanks to its modulation in biochemical composition throughout lactation. The short- and long-term benefits of human milk (HM) feeding are especially relevant for preterm infants and those with very low birth weights, as recommended by the World Health Organization and the American Academy of Pediatrics. However, when MOM is not available, donor HM represents the best alternative. The main benefits of using donor HM for preterm infant feeding are a reduction in the incidences of necrotizing enterocolitis, sepsis and bronchopulmonary dysplasia, as well as an enhanced feeding tolerance (Meier, Patel, \& Esquerra-Zwiers, 2017; Villamor-Martínez et al., 2018).

Donor HM has to be pasteurized for safety reasons, and the current method adopted in HM banks is the Holder pasteurization method (HoP, $62.5^{\circ} \mathrm{C}$ for $30 \mathrm{~min}$ ). HoP has been reported to cause the loss and/ or a reduction in the activity of important functional milk components, including immunoglobulins, lactoferrin, lysozyme, some cytokines and bile salt-stimulated lipase (BSSL), such as reviewed previously (Peila et al., 2016).

High-temperature short-time pasteurization (HTST, $72{ }^{\circ} \mathrm{C}$ for $15 \mathrm{~s}$ ) has been proved to be a promising alternative to the HoP method, as it offers a better retention of the bioactive HM compounds, while ensuring microbiological safety. Different studies have reported the effectiveness of the HTST method in eradicating the cytomegalovirus (Goldblum et al., 1984; Hamprecht et al., 2004) and pathogenic bacteria (Dhar, Fichtali, Skura, Nakai, \& Davidson, 1996; Escuder-Vieco et al., 2018). Compared to HoP, the HTST treatment of HM results in a higher retention of lactoferrin and immunoglobulins (IgA, IgG, IgM), as well as a

\footnotetext{
* Corresponding author.

E-mail addresses: stefano.nebbia@inrae.fr (S. Nebbia), marzia.giribaldi@crea.gov.it (M. Giribaldi), laura.cavallarin@ispa.cnr.it (L. Cavallarin), enrico.bertino@unito.it (E. Bertino), alessandra.coscia@unito.it (A. Coscia), valerie.briard-bion@inrae.fr (V. Briard-Bion), jordane.ossemond@inrae.fr (J. Ossemond), gwenaele.henry@inrae.fr (G. Henry), olivia.menard@inrae.fr (O. Ménard), didier.dupont@inrae.fr (D. Dupont), amelie.deglaire@agrocampus-ouest.fr (A. Deglaire).
} 
higher preservation of the antioxidant and antimicrobial activities (Baro et al., 2011; Peila et al., 2017; Mayayo et al., 2016; Donalisio et al., 2018; Escuder-Vieco, Espinosa-Martos, Rodríguez, Fernández, \& Pallás-Alonso, 2018).

A benchtop HTST pasteurizer has been patented and validated for the treatment of HM (Giribaldi et al., 2016). Its efficacy in eradicating common pathogens has been proved, as well as its ability to retain a higher antiviral activity (Donalisio et al., 2018) and a higher amount of some nutritive and immunological components than HoP (Giribaldi et al., 2016).

It has recently been demonstrated, through dynamic in vitro digestion under preterm conditions (De Oliveira, Deglaire, et al., 2016; Deglaire et al., 2019), that HoP modulates the gastrointestinal disintegration of HM and the bioaccessibility of some nutrients. In particular, it has been demonstrated that pasteurization does not affect gastric proteolysis, but instead modulates some amino acid and fatty acid bioaccessibilities, as well as the profile of the released peptides over the gastrointestinal digestion. Researchers currently agree about a differential effect of HoP and HTST on the quality of donor HM (Moro et al., 2019). The hypothesis behind the present research is that such compositional and nutritional differences may result in a differential digestion and, eventually, in a differential nutritional/functional availability of HM components.

To this aim, the proteolysis and lipolysis phenomena of raw, HoP and HTST HM were assessed using the innovative dynamic in vitro system $\left(\right.$ DIDGI $^{\circledast}$ ) mimicking preterm gastrointestinal digestion.

\section{Methods}

All the chemicals and enzymes were purchased from Sigma-Aldrich (Saint Quentin Fallavier, France), unless otherwise stated.

\subsection{Collection and pasteurization of the human milk}

Mature HM was obtained from the donor HM bank located at the Regina Margherita Children's Hospital, Turin (Italy). Each milk donor involved in the research signed a written consent form, which stated that protection of the mothers' and infants' data was ensured. Term donor milk was obtained from 5 healthy donors, from one to three months after term delivery, and stored at $-20{ }^{\circ} \mathrm{C}$, for a maximum of four months. The HM samples were thawed and pooled to achieve a final volume of about 1.7 L. The pooled milk was then divided into 120 $\mathrm{mL}$ aliquots $(n=12)$ and $40-\mathrm{mL}$ aliquots $(n=6)$. A third of the aliquots were immediately stored at $-20{ }^{\circ} \mathrm{C}$ (raw human milk, RHM), while the other aliquots underwent either $\mathrm{HoP}\left(62.5^{\circ} \mathrm{C}\right.$ for $\left.30 \mathrm{~min}\right)$ or HTST pasteurization $\left(72{ }^{\circ} \mathrm{C}\right.$ for $\left.15 \mathrm{~s}\right)$. HoP was performed using the donor HM bank equipment (Metalarredinox, Verdellino, BG, Italy), while HTST was performed by means of a patented proprietary smallscale device (Giribaldi et al., 2016).

\subsection{Human milk characterization}

\subsubsection{Macronutrient composition}

The macronutrient composition RHM and pasteurized HM samples was assessed by means of infrared spectrophotometry, using a Human Milk Analyzer (Miris AB, Uppsala, Sweden), previously validated against reference methods (Billard et al., 2016). The total lipid composition in the HM, before digestion, was determined by means of gas chromatography, coupled with a flame ionization detector, after direct transmethylation, as described by de Oliveira, Bourlieu, et al. (2016).

\subsubsection{Profiling of the intact protein by means of liquid} chromatography-mass spectrometry ( $L C-M S$ )

An analysis of the intact proteins was performed using a reversedphase high-performance liquid chromatography system (RP-HPLC, HPLC 1100 by Agilent Technologies, Santa Clara, CA), fitted with a Q-
Exactive mass spectrometer (Thermo Scientific Waltham, MA). Samples were diluted in $0.212 \%$ trifluoracetic acid (TFA) before injection. A 40$\mu \mathrm{L}$ injection volume was adopted and the oven temperature was set at $40{ }^{\circ} \mathrm{C}$. Proteins were separated on a C4 VYDAC column (214TP5215, $150 \times 2.1 \mathrm{~mm}$; Grace, Columbia, MD). A flow of $0.25 \mathrm{~mL} / \mathrm{min}$ was applied, using an acetonitrile (ACN) gradient of $0.106 \%(\mathrm{v} / \mathrm{v})$ TFA in water (A) and $0.1 \%(\mathrm{v} / \mathrm{v})$ TFA in $80 \%$ ACN (B). A fraction of the eluate was introduced into the Q-Exactive MS at the end of the column at a flow rate of $75 \mu \mathrm{L} / \mathrm{min}$. An electrospray MS, operating in positive ion mode, with an optimized voltage of $4.2 \mathrm{kV}$, was used to identify the intact proteins. Signals were recorded using an UV detector at $214 \mathrm{~nm}$. Spectra were recorded in full MS mode and selected over a $\mathrm{m} / \mathrm{z}$ 400-3000 mass range, with a resolution of 17500 . The instrument was calibrated externally, according to the supplier's instructions. The ions recovered in the sample were analyzed from the MS spectra using Xcalibur 2.2 Software (Thermo Scientific). The proteins were identified by manual search and match of different $m / z$ charges deriving from the most intense signals for each peak, due to the complexity of the signals, as caused by the presence of several charged statuses, and of minor proteins.

\subsubsection{Characterization of the milk fat globule associated proteins}

The milk fat globule associated proteins (MFGP) were extracted, as described by Barello et al. (2008). Briefly, samples were centrifuged at $5000 \mathrm{~g}$ for $30 \mathrm{~min}$ at $6{ }^{\circ} \mathrm{C}$, the pellet was discharged, and the supernatant was ultracentrifuged at $189000 \mathrm{~g}$ for $70 \mathrm{~min}$ at $6^{\circ} \mathrm{C}$. The fat globules were washed three times with $0.9 \%(\mathrm{w} / \mathrm{v}) \mathrm{NaCl}$ and re-suspended for $1 \mathrm{~h}$ in $1 \%(\mathrm{w} / \mathrm{v}$ ) ASB-14, $7 \mathrm{M}$ urea, $2 \mathrm{M}$ thiourea and $20 \mathrm{mM}$ tris(hydroxymethyl)aminomethane (Tris). The re-suspended protein solution was recovered and precipitated with methanol/chloroform, as described in Wessel and Flügge (1984). Proteins were solubilized in a NuPAGE $^{\circledast}$ LDS sample buffer (Thermo-Fisher Scientific), and the protein concentration was determined by means of a 2-D Quant-Kit (GE Healthcare, Boston, MA). Proteins ( $5 \mu \mathrm{g}$ ) were separated in triplicate from pasteurized and RHM under non-reducing conditions on 4-12\% gradient NuPAGE ${ }^{\circledR}$ Novex Bis-Tris precast gels (Thermo-Fisher Scientific), as previously described (De Oliveira, Bourlieu, et al., 2016), and the gels were stained with Colloidal Coomassie Blue (Candiano et al., 2004). Gel images were acquired using a ChemiDoc ${ }^{\mathrm{TM}}$ Imaging System (Bio-Rad, Hercules, CA) and saved at a 300 dpi resolution. Densitometric analysis was performed, using an ImageLab 6.0 software package (Bio-Rad). The relative intensity of each protein band in each lane was calculated as the symmetrized percentage change (SPC) in band volume with respect to a raw HM sample (Berry \& Ayers, 2006).

\subsubsection{Identification of the human milk proteins from gel electrophoresis}

Bands showing a significant variation between treatments were cut, digested and identified by means of MS. The bands were first reduced in $10 \mathrm{mM}$ DL-dithiothreitol (DTT) $/ 50 \mathrm{mM} \mathrm{NH}{ }_{4} \mathrm{HCO}_{3}$ for $45 \mathrm{~min}$ at $56{ }^{\circ} \mathrm{C}$, and then by alkylation, in $55 \mathrm{mM}$ iodoacetamide/ $50 \mathrm{mM} \mathrm{NH}_{4} \mathrm{HCO}_{3}$, for $30 \mathrm{~min}$ in the dark, at room temperature. The bands were then sequentially washed with water, $50 \%(\mathrm{v} / \mathrm{v}) \mathrm{ACN} / 50 \mathrm{mM} \mathrm{NH}_{4} \mathrm{HCO}_{3}, 100 \%$ ACN and $50 \%(\mathrm{v} / \mathrm{v}) \mathrm{ACN} / 50 \mathrm{mM} \mathrm{NH}{ }_{4} \mathrm{HCO}$. Gel pieces were dried in a vacuum concentrator (Eppendorf, Hamburg, Germany) and digested overnight at $37{ }^{\circ} \mathrm{C}$ under shaking, using $75 \mathrm{ng} / \mu \mathrm{L}$ porcine trypsin

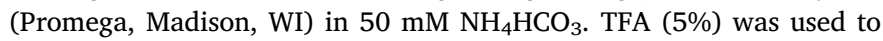
stop the enzymatic reaction.

The resulting peptides were analyzed using a Dionex U3000 nanoRSLC system fitted with a Q-Exactive MS, equipped with a nanoelectrospray ion source. The injection volume was $5 \mu \mathrm{L}$. Peptides were separated in a C18 PepMap column $(150 \mathrm{~mm} \times 75 \mu \mathrm{m}$; Thermo Scientific). The applied flow was $0.3 \mathrm{~mL} / \mathrm{min}$, with a gradient of $2 \%(\mathrm{v} /$ v) ACN, $0.08 \%(\mathrm{v} / \mathrm{v})$ formic acid, $0.01 \%(\mathrm{v} / \mathrm{v})$ TFA in water (A) and $95 \%(\mathrm{v} / \mathrm{v}) \mathrm{ACN}, 0.08 \%(\mathrm{v} / \mathrm{v})$ formic acid and $0.01 \%(\mathrm{v} / \mathrm{v})$ TFA in water (B). An electrospray mass spectrometer, operating in positive ion mode, was used with an optimized voltage of $1.9 \mathrm{kV}$. Mass spectra were 
recorded in the $m / z 250-2000$ range, with a resolution of 17500 , and MS/MS fragmentation was performed on the 10 most abundant ions. The obtained spectra were analyzed using X!Tandem (CYCLONE 2013.02.01.1), with reference to the UniProt Homo sapiens database (version 2017-10-01). The parameters set for the database search were: trypsin as the digestion enzyme; two possible missed cleavages; a mass error of $10 \mathrm{ppm}$ for the peptides and $0.05 \mathrm{Da}$ for the ions; oxidation of the methionine and phosphorylation of serine, threonine and tyrosine, as possible post-translational modifications.

\subsubsection{Analysis of the microstructure of the human milk by means of} confocal microscopy

The microstructure of the undigested RHM, HoP and HTST in the human milk samples was observed, using Nikon C1Si confocal laser scanning microscopy (CLSM), on a TE2000-E inverted microscope (Nikon, Champigny-sur-Marne, France), as previously described by Bourlieu et al. (2015). A $40 \times$ oil-immersion objective was used for all the images. Two fluorescent dyes, Fast Green ${ }^{\circledR}$, and LipidTOX ${ }^{\circledR}$, were used to simultaneously color proteins and apolar lipids, respectively.

\subsection{In vitro dynamic digestion}

The RHM, HoP and HTST samples were subjected to gastrointestinal digestion using the DIDGI ${ }^{\circledast}$ bi-compartmental in vitro dynamic system (Ménard et al., 2014). The system was set up to simulate the digestion of a preterm newborn at a postnatal age of four weeks. The specific gastrointestinal parameters have already been presented (De Oliveira, Bourlieu, et al., 2016) and are summarized in Supplementary data Table 1. The transit time of the fluids based on the Elashoff equation, with $t_{1 / 2}=36 \mathrm{~min}$ and $\beta=1.15$ for gastric emptying and $t_{1 / 2}=200$ and $\beta=2.2$ for intestinal emptying. The $\mathrm{pH}$ acidification in the gastric compartment followed a polynomial curve according to previous in vivo studies, as reviewed by Bourlieu et al. (2014), and updated with recent data obtained from de Oliveira et al. (2017):

$\mathrm{pH}$ acidification $=8 \mathrm{E}-05 *$ time $^{2}-0.031 *$ time +6.80

The intestinal $\mathrm{pH}$ was maintained constant at 6.2. Gastric enzymes, consisting of rabbit gastric extract (pepsin and lipase: 120 and $8.6 \mathrm{U} /$ $\mathrm{mL}$ of gastric content, respectively), and intestinal enzymes, consisting of rabbit porcine pancreatin (trypsin, and lipase: 1.52 and $59 \mathrm{U} / \mathrm{mL}$ of intestinal content) were added, together with bovine bile salts.

Digestion experiments were performed in triplicate for each matrix over three hours. Aliquots were collected before digestion and at 30, 60, and $90 \mathrm{~min}$ after the beginning of the digestion in both the gastric and intestinal compartments. Additional samples were collected from the intestinal compartment at 120 and $180 \mathrm{~min}$. Structural analyses (particle size distribution profiling) were performed immediately. The samples for lipid analysis were processed immediately for lipid extraction, after the addition of $5 \mathrm{mg}$ of 4-bromophenylboronic acid per $\mathrm{mL}$ of digest as a lipase inhibitor. Aliquots of $10 \mu \mathrm{L}$ of pepstatin A $(0.72 \mathrm{mM})$ per $\mathrm{mL}$ of gastric digest or $50 \mu \mathrm{L}$ of Pefabloc $^{\oplus}(0.1 \mathrm{M})$ per $\mathrm{mL}$ of intestinal digest were added immediately as protease inhibitors, and the samples were then stored at $-20{ }^{\circ} \mathrm{C}$ until analysis.

\subsubsection{Particle size distribution of the human milk during gastric digestion}

The distribution of the size of the particles before and during gastric digestion of the differently treated HM was profiled using a Mastersizer 2000 (Malvern Instruments, Malvern, UK) laser light scattering device, equipped with two laser sources, as previously described (Bourlieu et al., 2015). The used refractive indices were 1.458 for the lipids at 633 and $466 \mathrm{~nm}$ and 1.333 for the water (dispersant solution) in the measurement cell. The diameter mode, the diameter mean $\mathrm{D}[4,3]$ and the specific surface (SS) were calculated from the size distribution.

\subsubsection{Determination of the protein hydrolysis degree $(\mathrm{DH})$ of the human} milk

The DH was calculated by measuring the primary amines $\left(-\mathrm{NH}_{2}\right)$ released during in vitro digestion, using a microplate analysis based on the reaction of ortho-phthaldialdehyde (OPA) and DTT, with primary amines, which resulted in 1-alkylthio-2-alkylisondole being detected at $340 \mathrm{~nm}$, as previously described by Deglaire et al. (2019). The total releasable primary amines $\left(\mathrm{NH}_{2}\right.$ (total)) were also determined in an $\mathrm{HM}$ sample before digestion, following total acid hydrolysis in $6 \mathrm{~N} \mathrm{HCl}$ at $110{ }^{\circ} \mathrm{C}$ for $24 \mathrm{~h}$. The $\mathrm{DH}$ was calculated as follows:

$$
\begin{aligned}
& \mathrm{DH}(\%) \\
& =\frac{100 \times\left(\left[\frac{\mathrm{mg}}{\mathrm{L}} \mathrm{NH} 2(\mathrm{t})\right] \times \text { digestion dilution factor }-\left[\frac{\mathrm{mg}}{\mathrm{L}} \mathrm{NH} 2(\mathrm{t} 0)\right]\right)}{\frac{\mathrm{mg}}{\mathrm{L}} \mathrm{NH} 2(\text { total })}
\end{aligned}
$$

where $[\mathrm{NH} 2(\mathrm{t})]$ is the concentration of primary amines after $\mathrm{t}$ min of digestion and $[\mathrm{NH} 2(\mathrm{t} 0)]$ is the concentration of primary amines in each original HM sample before digestion.

\subsubsection{Profiling of human milk protein digestion by means of gel electrophoresis}

Protein electrophoresis was performed on the original HM samples and on the gastric and intestinal digests, under both reducing and nonreducing conditions. After quantification of the protein concentration in the undigested HM samples (RHM, HoP and HTST), conducted using a 2-D Quant-Kit, 3 and $30 \mu \mathrm{g}$ of proteins were separated on gels for the gastric and intestinal digests, respectively. The total proteins were diluted in a NuPAGE ${ }^{\circledast}$ LDS sample buffer, and electrophoresis and image acquisition were performed according to the procedure described in Section 2.2.3.

In order to minimize variations between the different gels, a densitometric analysis was performed on the relative quantity of the gel bands, as calculated by means of the ImageLab software package, by standardizing the volume of each band in each gel to the volume of a reference band (in our approach, a native lactoferrin band in an undigested RHM sample). The relative abundance of each band, at each digestion stage, was then calculated with respect to its value in the RHM sample before digestion and expressed as a \% of the undigested milk quantity. Bands showing significant variations between the pasteurization treatments were cut and digested, and then identified by means of mass spectrometry, as described in Section 2.2.4.

\subsubsection{Quantification of the amino acid release from the human milk during intestinal digestion}

The released quantity of each amino acid (AA) was determined as detailed elsewhere (De Oliveira, Bourlieu, et al., 2016). Cysteine and proline were under the detection limit and no tryptophan was quantified in the total AA. AA bioaccessibility was calculated as follows:

AA bioaccessibility $(\%)=\frac{100 \times\left(\frac{\mathrm{mg}}{\mathrm{L}} \mathrm{AA}(\mathrm{t}) \times \text { digestion dilution factor }\right)}{\frac{\mathrm{mg}}{\mathrm{L}} \mathrm{AA}(\text { total })}$

where $\mathrm{AA}(\mathrm{t})$ is the amount of AA after $t$ min of digestion and AA(total) is the amount of each AA that was obtained after total acid hydrolysis in $6 \mathrm{~N} \mathrm{HCl}$ at $110{ }^{\circ} \mathrm{C}$ for $24 \mathrm{~h}$ of undigested milk.

The total amino acid release was calculated as the sum of all the AA released at digestion time $(t)$, divided by the total AA in the undigested milk obtained after acid hydrolysis.

\subsubsection{Lipid analysis}

Lipid extraction was performed as previously described (Bourlieu et al., 2015). The lipid classes were quantified by means of thin layer chromatography. The extracted lipids were spotted on silica gel plates $(10 \times 20 \mathrm{~cm}, 0.25 \mathrm{~mm}$, Si G60; Merck), using an Automated TLC Sampler III (CAMAG, Muttenz, Switzerland). The lipid classes were separated, utilizing a solvent mixture of hexane/diethyl ether/acetic 
acid $(70 / 30 / 2 \mathrm{v} / \mathrm{v} / \mathrm{v})$, revealed by means of a copper sulfate/orthophosphoric acid solution and heated for $15 \mathrm{~min}$ at $150{ }^{\circ} \mathrm{C}$. The visible band images on the plates were scanned using an Image Scanner III (GE Healthcare) at a resolution of $300 \mathrm{dpi}$. A densitometric analysis was performed using Image Quant $\mathrm{TL}^{\mathrm{TM}}$ (GE Healthcare). Triacylglycerol (TAG) digestion was estimated as the percentage of TAG remaining in the gastric and intestinal digests at each considered time, compared with the total TAG in the undigested milk.

\subsection{Statistical analyses}

All the statistical analyses were performed using PAST software, version 3 (Hammer, Harper, \& Ryan, 2001). A $p \leq 0.05$ probability was considered as statistically significant. Results were expressed as the means \pm standard deviation (SD), unless otherwise stated.

The abundance in the undigested HM samples of the MFGP bands (expressed as SPC) and of the soluble protein bands (expressed as relative abundance) were analyzed using one-way ANOVA. Normality of the residuals was assessed by means of Shapiro-Wilk's test. Where significance was assessed, post hoc tests were conducted using Tukey's multiple comparison post hoc test. When unequal variances and/or lack of normality were found, the Kruskal-Wallis test was used, coupled with Dunn's post hoc test.

Data from the profiling of differently pasteurized HM (RHM, HoP and HTST) during digestion were analyzed for significance at $p \leq 0.05$ by means of two-way ANOVA, with the digestion time and pasteurization treatment as factors. When significance was observed, post hoc tests were conducted, using Tukey's multiple comparison test.

\section{Results}

\subsection{Human milk characterization before digestion}

The raw and pasteurized HM samples (RHM, HoP, HTST) showed a similar macronutrient composition $(27.7 \pm 1.5 \mathrm{~g} / \mathrm{L}$ of lipids, $8.0 \pm 0.1 \mathrm{~g} / \mathrm{L}$ of proteins and $82.3 \pm 1.2 \mathrm{~g} / \mathrm{L}$ of carbohydrates) prior to digestion. The RHM lipid fraction contained $40.3 \%(\mathrm{w} / \mathrm{w})$ of saturated fatty acids, $46.5 \%(\mathrm{w} / \mathrm{w})$ of MUFAs and $13.2 \%(\mathrm{w} / \mathrm{w})$ of PUFAs. The $\omega 6 / \omega 3$ PUFA ratio was 9.9 . The lipid profile was dominated by six main FAs: oleic (44 $\pm 0.1 \%$ ), palmitic (20.4 $\pm 0.1 \%$ ), linoleic $(10.7 \pm 0.1 \%)$, stearic $(5.9 \pm 0.1 \%)$, myristic $(5.6 \pm 0.1 \%)$ and lauric $(5.1 \pm 0.1 \%)$ acids.

Confocal microscopy observation of the HM samples prior to digestion (Fig. 1A) showed that both pasteurization methods led to heatinduced protein aggregates (blue dots), in both the soluble phase and at the interface of the HM fat globule membrane. The protein-fat interaction phenomenon, which was somewhat observed in the RHM, was more noticeable following HoP than following HTST. However, no difference in the particle size distribution was observed in the different milk samples before digestion (Fig. 1B - G0). All the samples showed a bimodal distribution, with a main peak between 6.4 and $7 \mu \mathrm{m}$ (Fig. 1CG0).

LC-MS separation of the soluble intact proteins of the RHM, HoP and HTST samples allowed three major protein fractions and two minor protein peaks to be detected (Supplementary data Fig. 1). The peak identified as human lactoferrin showed a higher area in the HTST milk than in the HoP milk ( $75 \%$ vs. 33\% of the protein peak area in RHM). Native $\alpha$-lactalbumin was identified in all the samples, whereas its $\mathrm{Na}^{+}$ adduct was only detected in the RHM.

The electrophoretic profile of the soluble proteins under the reducing (Fig. 2A) and non-reducing (Fig. 2B) conditions showed significant differences in the relative abundance of some specific bands among the RHM, HoP and HTST samples. Identification of the proteins within the bands is reported in Table 1. Under reducing conditions, only one faint band (band R2, Fig. 2A), containing macrophage mannose receptor 1, showed a significantly reduced $(-15 \%)$ abundance in HoP milk with respect to HTST. Under non-reducing conditions, several bands showed significant different intensities among samples. The band at $66 \mathrm{kDa}$ (10-12nr, Fig. 2B), corresponding to native lactoferrin (Table 1), presented a reduced intensity in HoP $(-70 \%)$ and in HTST $(-40 \%)$, with respect to RHM. Concomitantly, the intensity of the high molecular weight aggregates (bands 1-3nr, Fig. 2B), mainly composed of lactoferrin, increased in both pasteurized milk samples. The other proteins detected in these aggregates included fatty acid synthase, xanthine dehydrogenase, macrophage mannose receptor 1 and BSSL. The last was also identified in bands $8 \mathrm{nr}$ and $9 \mathrm{nr}$, which showed a significantly lower relative abundance in HoP $(-66 \%)$ and in HTST $(-39 \%)$ than in RHM.

The profile of the MFGPs (Fig. 2C), coupled to band identification (Table 1), also showed significant differences among samples. The high molecular weight aggregates (bands A-C, $2 \mathrm{C}$ ), also in this fraction, were more abundant for HoP $(+47 \%)$ and for HTST $(+25 \%)$, with respect to RHM. The increased number of identified peptides from lactoferrin and xanthine dehydrogenase indicated a specific increased abundance of these proteins in aggregates. Accordingly, the native lactoferrin band (F) significantly decreased in the MFGPs after HTST pasteurization (band $\mathrm{H},-38 \%$ ) and was almost undetectable in the MFGPs after HoP $(-78 \%)$. Overall, the common proteins involved in the formation of high molecular weight aggregates in both MFGPs and skimmed HM following pasteurization were lactoferrin, xanthine dehydrogenase, and fatty acid synthase. Band D in the MFGPs, which mainly contained BSSL, was also highly reduced after HTST (band E, $-60 \%$ ), and undetectable after HoP. The reduction of $\beta$-casein in band $\mathrm{P}$ after both pasteurization methods, corresponded to an increase in band $Q$, thus indicating a probable conformational rearrangement as a result of the thermal treatments. The same behavior was observed for the lysozymecontaining bands (S and T; Fig. 2C).

\subsection{Structural changes during gastric digestion}

Fig. 1B shows a profile of the particle size distribution of the raw and pasteurized HM samples during the simulated gastric digestion under preterm newborn conditions, with the corresponding particle size parameters (D[4,3], specific surface area and mode diameter). Although the particle size distribution of the undigested milks (G0) was similar regardless of the treatment, major differences were observed during digestion, with the formation of significantly larger aggregates in RHM (mode diameter $26-27 \mu \mathrm{m}$, specific surface area $0.4 \mathrm{~m}^{2} / \mathrm{g}$ fat) than in HTST and HoP (mode diameter 6.6-6.7 $\mu \mathrm{m}$, specific surface area $10-12.3 \mathrm{~m}^{2} / \mathrm{g}$ fat) after 60 and $90 \mathrm{~min}$ of gastric digestion (Fig. 1C). These aggregates were dissociated by addition of SDS (data not shown). On the other hand, the pasteurized HM samples did not show any modification of the particle size during gastric digestion (Fig. 1B - G60 and G90).

\subsection{Kinetics of proteolysis}

\subsection{1. $\mathrm{NH}_{2}$ release after $\mathrm{HM}$ digestion}

The proportion of $\mathrm{NH}_{2}$ released after gastric and intestinal digestion was not significantly different in the raw and pasteurized milks. A mean $\mathrm{NH}_{2}$ release of $1.7 \pm 0.5 \%$ was determined in the gastric phase for the three types of milk. Intestinal digestion led to an increase in the release of $\mathrm{NH}_{2}$ of up to $46 \pm 0.6 \%$ at the end of the gastrointestinal digestion (data not shown).

\subsubsection{Gastric proteolysis}

The electrophoretic protein profiles of the gastric digests under reducing $\left(A_{R}\right)$ and non-reducing $\left(A_{N R}\right)$ conditions are reported in Fig. 3 and the relative abundance of the bands showing significant variations among samples in Fig. 4. The band identification is detailed in Table 1. The majority of the significant variations in band abundance occurred between RHM and both of the pasteurized samples, irrespective of the 
A)
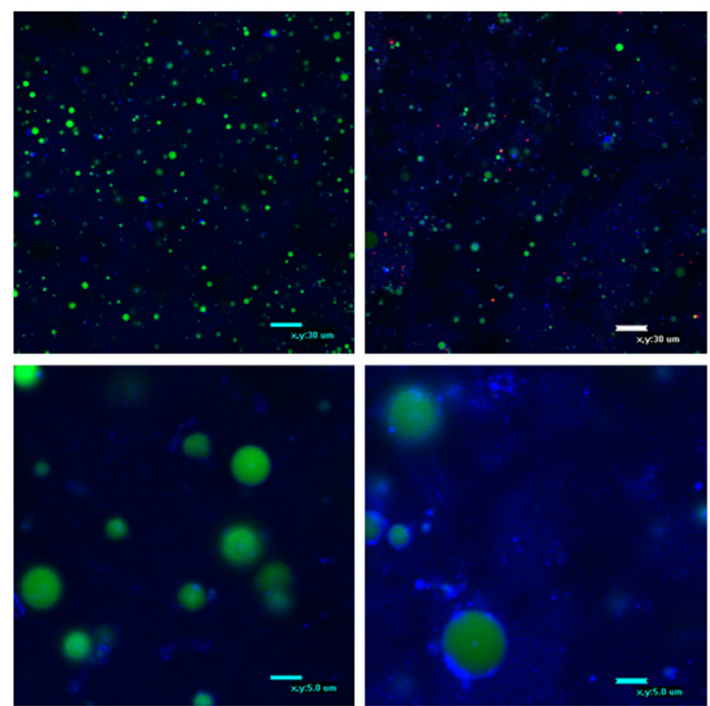

Undigested RHM

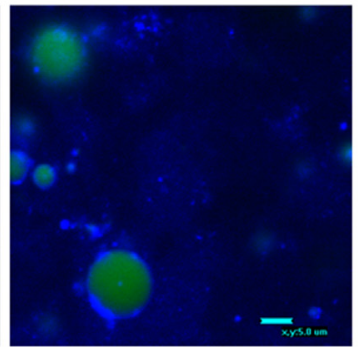

Undigested HoP
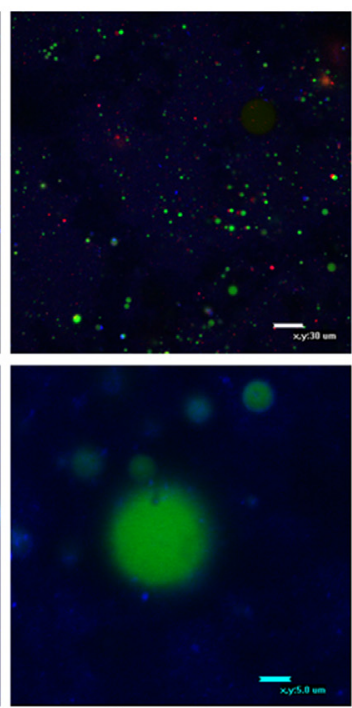

Undigested HTST
B)

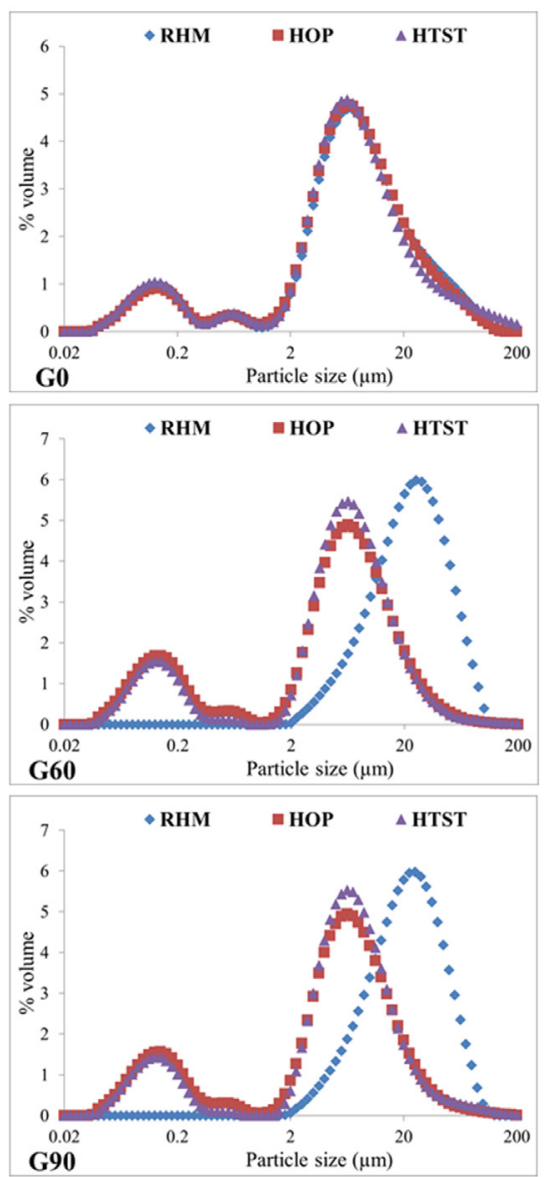

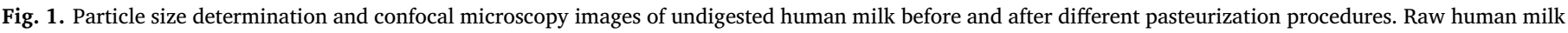

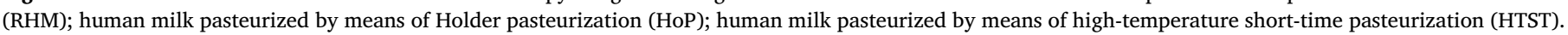

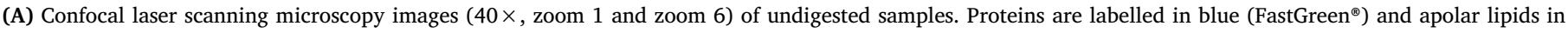

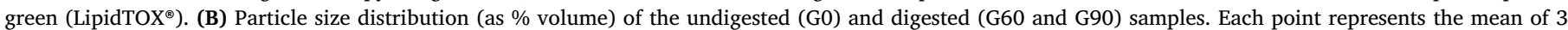

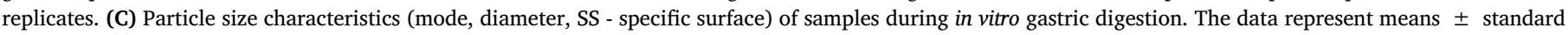

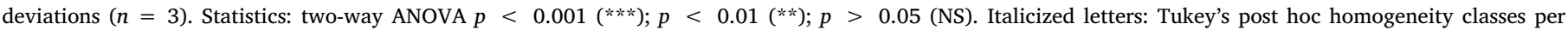
treatment. (For interpretation of the references to color in this figure legend, the reader is referred to the web version of this article.)

running conditions. The common trends in pasteurized HM samples resulted in a faster gastric proteolysis of high molecular weight protein bands, including lactoferrin, with respect to RHM (Fig. 4A), whereas proteins in heat-induced aggregates (bands 1-2-3nr) displayed an almost steady trend in the gastric phase, irrespective of the processing treatment (Fig. 4B). Only one significant difference was found between the two different pasteurization methods, which was, for bands 4-5-6nr, a slightly reduced abundance in HoP than in RHM and HTST. The band mainly contained immunoglobulins, but also some lactoferrin, the latter being detected only in pasteurized samples (Table 1). No significant difference of gastric digestion was observed among the different samples for the other major proteins, such as $\beta$-casein, $\alpha$-lactalbumin, as well as serum albumin.

\subsubsection{Intestinal proteolysis}

The electrophoretic protein profiles of the intestinal digests, under reducing $\left(B_{R}\right)$ and non-reducing $\left(B_{N R}\right)$ conditions, are reported in Fig. 3, and the relative abundance of the bands showing significant variations between samples in Fig. 5. The protein identification in the bands is shown in Table 1. During intestinal proteolysis, the different digestion pattern of RHM with respect to both pasteurized samples was even more stressed. By using both the reducing and non-reducing conditions for the separation of the proteins, a faster proteolysis in both pasteurized samples was observed for bands containing higher molecular weight bands. In particular, the trend was marked for native lactoferrin (bands 10-12nr in Fig. 5B). The high-molecular-weight aggregates (bands 1-2-3nr) were soon digested to almost undetectable levels in all the samples (Fig. 3). At the beginning of intestinal digestion, pasteurization increased the resistance of serum albumin, with respect to RHM (Fig. 5A). Nevertheless, after $180 \mathrm{~min},<10 \%$ of intact serum albumin was detected in any sample.

The only significant difference during intestinal digestion between the two pasteurization methods was the slight, although significant, lower relative abundance in HoP for bands 4-5-6nr (Fig. 5B), which mainly contained immunoglobulins and lactoferrin.

The free AA profile of the HM samples was also determined and quantified during intestinal digestion (Fig. 5C and Supplementary Data Table 2). Although a significant difference in the amount of the released non-essential AAs was observed among RHM, HoP and HTST, the release of essential AAs, and, overall, of total AAs, was always similar between RHM and HTST, and significantly higher than in HoP.

\subsection{Triacylglycerol hydrolysis kinetics}

No significant difference of TAG hydrolysis was found in the gastric and intestinal phases between RHM, HoP and HTST in this study (Supplementary Data Fig. 2). The percentage decreased to $72.5 \pm 6.7 \%$ for RHM, $71.3 \pm 4.2 \%$ for HoP and $71.9 \pm 1.6 \%$ for HTST after $30 \mathrm{~min}$ of gastric digestion and remained quite stable afterwards. TAG hydrolysis was greatly increased after $30 \mathrm{~min}$ of 

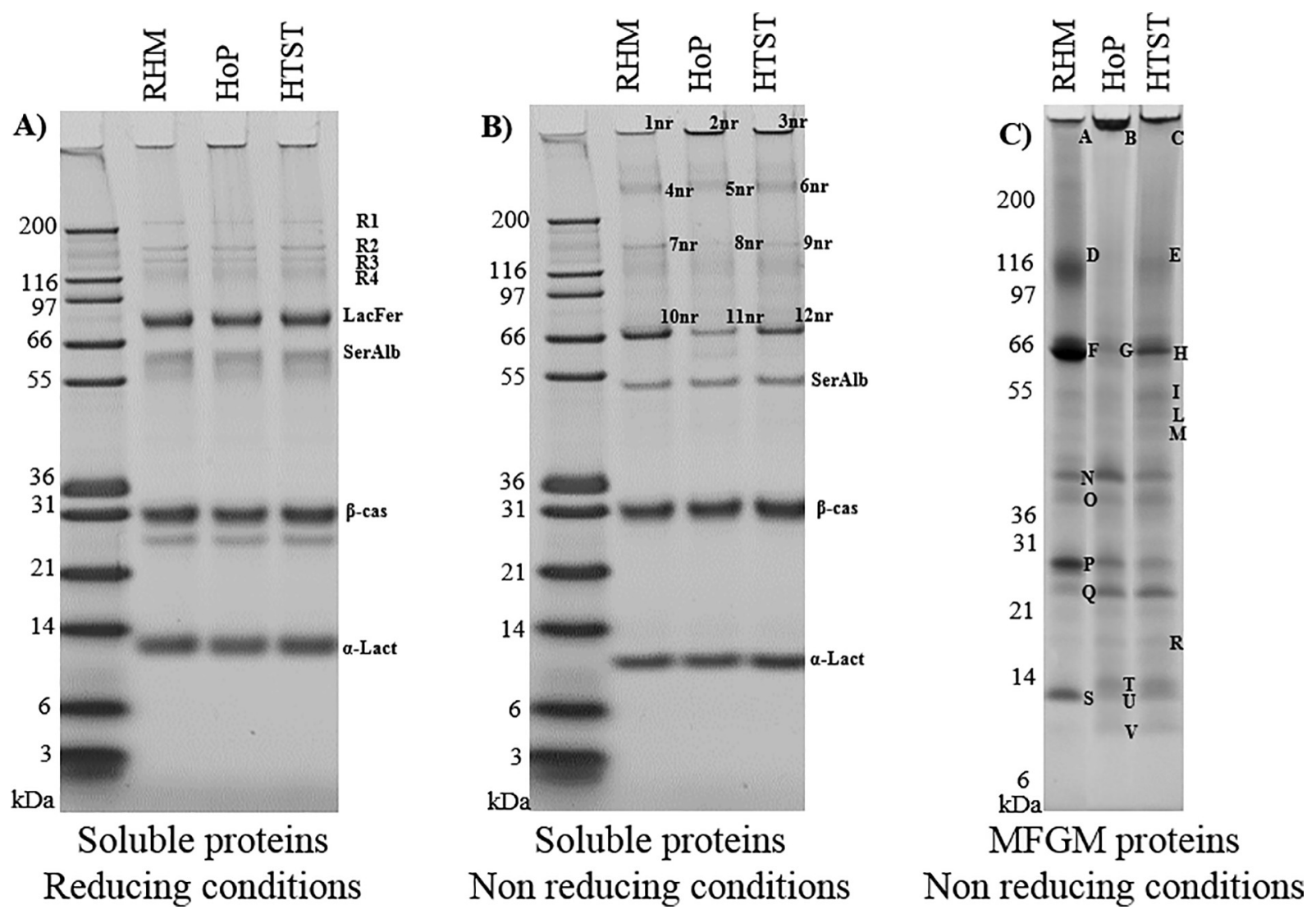

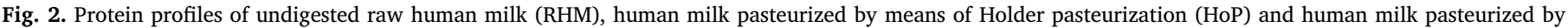

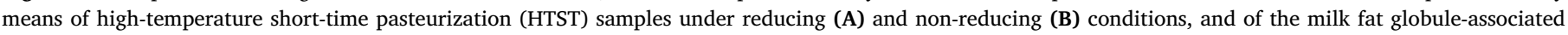

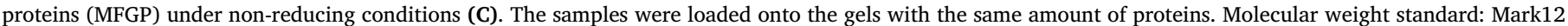

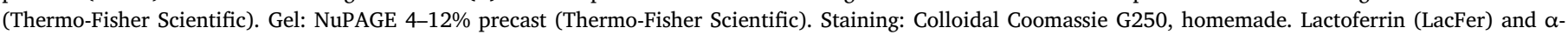

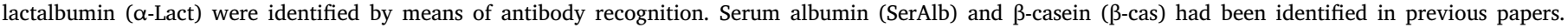
Differently coded protein bands were identified by means of LC-MS/MS (see Table 1).

intestinal digestion and, at the end of intestinal digestion, the remaining TAGs reached $32.2 \pm 1.9 \%$ for RHM, $34.3 \pm 6.3 \%$ for HoP and $29.3 \pm 0.8 \%$ for HTST of the initial quantity.

\section{Discussion}

The present study has evaluated, for the first time, whether different thermal pasteurization techniques may affect HM digestive kinetics in different ways in a preterm newborn in vitro model of dynamic digestion. To date, several reports have indicated that HTST pasteurization leads to a better preservation of mother's milk, in both nutritional and biological value terms, in comparison to the standard Holder technique (Peila et al., 2016). In particular, HTST-treated HM has been shown to have a higher secretory IgAs (sIgAs) content and a higher lysozyme (Giribaldi et al., 2016) than HoP-treated HM, as well as an improved preservation of the raw HM antiviral activity (Donalisio et al., 2018). Nevertheless, data about the possible implications of different pasteurisation methods on the digestion profile are lacking. In the present experiment, we have demonstrated that the standard Holder pasteurization technique and continuous-flow HTST exert rather similar digestive patterns regarding both lipids and proteins, although differences stand in terms of total and essential free AA release during intestinal digestion, being significantly higher for RHM and HTST than for HOP.

\subsection{Human milk characterization before digestion}

Both pasteurization processes affected the HM protein profile. In particular, the native lactoferrin content was notably reduced by pasteurization, albeit to a much lesser extent in the HTST than in the HoP samples. These results were expected from previous observations (Baro et al., 2011; Giribaldi et al., 2016) and such as reviewed previously (Peila et al., 2017).

The decrease of native lactoferrin content was due to its contribution to the formation of heat-induced soluble aggregates, with other minor proteins such as BSSL, macrophage mannose receptor 1 and xanthine dehydrogenase, which were linked by covalent disulfide bonds, as revealed by non-reducing SDS-PAGE analysis (Baro et al., 2011; Giribaldi et al., 2016). Interestingly, measuring lactoferrin content in the pasteurized HM samples, by means of ELISA tests, led to an underestimation of its concentration (data not shown), thus indicating that the structural modification, due to thermal processing, is responsible for epitope misrecognition by the antibody.

The observation of the milk microstructure, by means of confocal microscopy, revealed that protein aggregates were located in the soluble phase, as well as at the interface of the HM fat globule membrane, and that this type of aggregation seemed to be more visible in the HoP than in the HTST milk, although we did not quantify its extent. Some protein aggregation could be observed in RHM, which may be due to the freeze-thawing cycle.

The phenomenon of protein adhesion to a fat globule, observed in the present study, has already been observed using both confocal microscopy (De Oliveira, Bourlieu, et al., 2016; De Oliveira, Deglaire, et al., 2016) and a proteomic approach on RHM and HoP (Ma, Zhang, Wu, \& Zhou, 2019; Ye, Singh, Taylor, \& Anema, 2004). An analysis of the HM protein fraction associated with the fat globule membrane has been conducted here for the first time to gain deeper insight into the 
Table 1

Protein identification of the bands in Figs. 2 and 3 by means of LC-MS/MS

\begin{tabular}{|c|c|c|c|c|c|c|}
\hline Band & Identified protein & Entry (UniProt) & Theoretical/apparent MW (kDa) & Log (E value) & Coverage $(\%)$ & Matching/unique peptides $\left(\mathrm{n}^{\circ}\right)$ \\
\hline \multicolumn{7}{|c|}{ Identifications in Fig. 2A } \\
\hline R1 & Fatty acid synthase & P49327 & $273 />200$ & -27.6 & 2 & $7 / 7$ \\
\hline $\mathbf{R} 2$ & Macrophage mannose receptor 1 & P22897 & $166 / 150$ & -26.5 & 6 & $10 / 10$ \\
\hline R3 & Xanthine dehydrogenase/reductase & P47989 & $146 / 140$ & -24.0 & 6 & $9 / 9$ \\
\hline \multirow[t]{2}{*}{ R4 } & Bile salt-stimulated lipase & P19835 & $79 / 120$ & -18.6 & 6 & $6 / 5$ \\
\hline & Lactoferrin & P02788 & $77 / 120$ & -9.1 & 5 & $4 / 4$ \\
\hline \multicolumn{7}{|c|}{ Identifications in Fig. $2 \mathbf{B}$} \\
\hline \multirow[t]{3}{*}{$1 \mathrm{nr}$} & 1- Fatty acid synthase & P49327 & $273 />200$ & -40.9 & 5 & $12 / 12$ \\
\hline & 2- Butyrophilin subfamily 1 member A1 & Q13410 & $59 />200$ & -22.1 & 12 & $6 / 6$ \\
\hline & 3- Lactoferrin & P02788 & $78 />200$ & -20.9 & 10 & $7 / 7$ \\
\hline \multirow[t]{6}{*}{$2 n \mathbf{r}$} & 1- Lactoferrin & P02788 & $78 />200$ & -388.9 & 72 & $178 / 94$ \\
\hline & 2- Fatty acid synthase & P49327 & $273 />200$ & -114.1 & 11 & $28 / 28$ \\
\hline & 3- Macrophage mannose receptor 1 & P22897 & $166 />200$ & -88.1 & 15 & $22 / 21$ \\
\hline & 4- Xanthine dehydrogenase/oxidase & P47989 & $146 />200$ & -77.6 & 14 & $19 / 17$ \\
\hline & 5- Bile salt-stimulated lipase & P19835 & $79 />200$ & -66.2 & 18 & $17 / 14$ \\
\hline & 6- Butyrophilin subfamily 1 member A1 & Q13410 & $59 />200$ & -53.1 & 25 & $19 / 16$ \\
\hline \multirow[t]{6}{*}{$3 n \mathbf{r}$} & 1- Lactoferrin & P02788 & $78 />200$ & -241.8 & 62 & $101 / 65$ \\
\hline & 2- Fatty acid synthase & P49327 & $273 />200$ & -67.4 & 7 & $17 / 17$ \\
\hline & 3- Butyrophilin subfamily 1 member A1 & Q13410 & $59 />200$ & -50.0 & 25 & $14 / 14$ \\
\hline & 4- Xanthine dehydrogenase/oxidase & P47989 & $146 />200$ & -44.1 & 9 & $13 / 13$ \\
\hline & 5- Macrophage mannose receptor 1 & P22897 & $166 />200$ & -30.8 & 8 & $10 / 10$ \\
\hline & 6- Bile salt-stimulated lipase & P19835 & $79 />200$ & -19.8 & 8 & $6 / 6$ \\
\hline \multirow[t]{3}{*}{$4 \mathrm{nr}$} & 1- Polymeric immunoglobulin receptor & P01833 & $83 / 250$ & -24.9 & 7 & $7 / 7$ \\
\hline & 2- Immunoglobulin heavy constant alpha 1 & P01876 & $37 / 250$ & -23.6 & 20 & $10 / 7$ \\
\hline & 3- Immunoglobulin heavy constant alpha 2 & P01877 & $36 / 250$ & -17.8 & 12 & $4 / 4$ \\
\hline \multirow[t]{4}{*}{$5 \mathrm{nr}$} & 1- Lactoferrin & P02788 & $78 />200$ & -49.3 & 17 & $17 / 16$ \\
\hline & 2- Polymeric immunoglobulin receptor & P01833 & $83 />200$ & -30.1 & 9 & $8 / 7$ \\
\hline & 3- Immunoglobulin heavy constant alpha 1 & P01876 & $37 />200$ & -23.6 & 13 & $14 / 5$ \\
\hline & 4- Immunoglobulin heavy constant alpha 2 & P01877 & $36 />200$ & -17.2 & 9 & $6 / 3$ \\
\hline \multirow[t]{4}{*}{$6 \mathrm{nr}$} & 1- Immunoglobulin heavy constant alpha 1 & P01876 & $37 />200$ & -22.2 & 16 & $12 / 6$ \\
\hline & 2- Lactoferrin & P02788 & $78 />200$ & -21.8 & 9 & $7 / 7$ \\
\hline & 3- Polymeric immunoglobulin receptor & P01833 & $83 />200$ & -21.8 & 6 & $6 / 5$ \\
\hline & 4- Immunoglobulin heavy constant alpha 2 & P01877 & $37 />200$ & -13.4 & 12 & $5 / 4$ \\
\hline $7 \mathrm{nr}$ & Unidentified & & & & & \\
\hline $8 \mathrm{nr}$ & 1- Macrophage mannose receptor 1 & P22897 & $166 / 150$ & -35.3 & 7 & $12 / 10$ \\
\hline & 2- Xanthine dehydrogenase/oxidase & P47989 & $147 / 150$ & -25.6 & 6 & $10 / 10$ \\
\hline & 3- Bile salt-stimulated lipase & P19835 & $79 / 150$ & -8.3 & 3 & $3 / 3$ \\
\hline $9 \mathrm{nr}$ & Bile salt-stimulated lipase & P19835 & $79 / 150$ & -20.9 & 9 & $8 / 8$ \\
\hline $10 \mathrm{nr}$ & Lactoferrin & P02788 & $78 / 66$ & -198.0 & 50 & $126 / 60$ \\
\hline $11 \mathrm{nr}$ & Lactoferrin & P02788 & $78 / 66$ & -97.9 & 30 & $44 / 28$ \\
\hline $12 \mathrm{nr}$ & Lactoferrin & P02788 & $78 / 66$ & -314.95 & 66 & $144 / 86$ \\
\hline Identi & cations in Fig. $2 \mathrm{C}$ & & & & & \\
\hline A & 1- Fatty acid synthase & P49327 & $273 />200$ & -307.8 & 28 & $93 / 91$ \\
\hline & 2- Xanthine dehydrogenase/oxidase & P47989 & $146 />200$ & -114.1 & 18 & $30 / 29$ \\
\hline & 3- Butyrophilin subfamily 1 member A1 & Q13410 & $59 />200$ & -95.6 & 32 & $41 / 30$ \\
\hline & 4- Lactoferrin & P02788 & $78 />200$ & -94.2 & 35 & $26 / 26$ \\
\hline B & 1- Fatty acid synthase & P49327 & $273 />200$ & -268.8 & 25 & $81 / 80$ \\
\hline & 2- Xanthine dehydrogenase/oxidase & P47989 & $146 />200$ & -184.1 & 27 & $71 / 58$ \\
\hline & 3- Lactoferrin & P02788 & $78 />200$ & -183.3 & 58 & $63 / 53$ \\
\hline & 4- Butyrophilin subfamily 1 member A1 & Q13410 & $59 />200$ & -89.6 & 34 & $36 / 27$ \\
\hline C & 1- Fatty acid synthase & P49327 & $273 />200$ & -327.2 & 30 & $100 / 94$ \\
\hline & 2- Xanthine dehydrogenase/oxidase & P47989 & $146 />200$ & -260.2 & 36 & $104 / 75$ \\
\hline & 3- Lactoferrin & P02788 & $78 />200$ & -211.4 & 59 & $81 / 73$ \\
\hline & 4- Butyrophilin subfamily 1 member A1 & Q13410 & $59 />200$ & -87.8 & 32 & $39 / 30$ \\
\hline D & 1- Bile salt-stimulated lipase & P19835 & $79 / 116$ & -216.2 & 40 & $129 / 73$ \\
\hline & 2- Lactoferrin & P02788 & $78 / 116$ & -157.8 & 53 & $46 / 46$ \\
\hline & 3- Butyrophilin subfamily 1 member A1 & Q13410 & $59 / 116$ & -55.7 & 27 & $28 / 21$ \\
\hline $\mathbf{E}$ & 1- Lactoferrin & P02788 & $78 / 116$ & -49.0 & 20 & $21 / 19$ \\
\hline & 2 -Butyrophilin subfamily 1 member A1 & Q13410 & $59 / 116$ & -44.1 & 21 & $21 / 16$ \\
\hline & 3- Bile salt-stimulated lipase & P19835 & $79 / 116$ & -37.3 & 10 & $15 / 12$ \\
\hline $\mathbf{F}$ & Lactoferrin & P02788 & $78 / 66$ & -807.3 & 86 & $582 / 210$ \\
\hline G & Lactoferrin & P02788 & $78 / 66$ & -83.6 & 27 & $38 / 28$ \\
\hline $\mathbf{H}$ & Lactoferrin & P02788 & $78 / 66$ & -246.1 & 60 & $126 / 70$ \\
\hline I & Butyrophilin subfamily 1 member & Q13410 & $59 / 55$ & -119.0 & 34 & $66 / 37$ \\
\hline $\mathbf{L}$ & 1- Butyrophilin subfamily 1 member & Q13410 & $59 / 52$ & -64.8 & 28 & $33 / 23$ \\
\hline & 2- Serum albumin & P02768 & $69 / 52$ & -31.5 & 18 & $11 / 11$ \\
\hline $\mathbf{M}$ & 1- Lactoferrin & P02788 & $78 / 50$ & -18.0 & 6 & $6 / 6$ \\
\hline & 2- Lactadherin & Q08431 & $43 / 50$ & -13.2 & 15 & $7 / 7$ \\
\hline $\mathbf{N}$ & Lactadherin & Q08431 & $43 / 43$ & -74.5 & 31 & $25 / 22$ \\
\hline $\mathbf{O}$ & Lactadherin & Q08431 & $43 / 40$ & -69.7 & 34 & $27 / 21$ \\
\hline $\mathbf{P}$ & 1- $\beta$-Casein & P05814 & $25 / 28$ & -24.6 & 31 & $15 / 8$ \\
\hline & 2- Apolipoprotein & P02647 & $31 / 25$ & -16.7 & 19 & $8 / 7$ \\
\hline $\mathbf{Q}$ & $\beta$-Casein & P05814 & $25 / 25$ & -4.6 & 8 & $3 / 2$ \\
\hline
\end{tabular}


Table 1 (continued)

\begin{tabular}{|c|c|c|c|c|c|c|}
\hline Band & Identified protein & Entry (UniProt) & Theoretical/apparent MW (kDa) & Log (E value) & Coverage (\%) & Matching/unique peptides $\left(\mathrm{n}^{\circ}\right)$ \\
\hline $\mathbf{R}$ & Unidentified & & & & & \\
\hline$S$ & Lysozyme & P61626 & $17 / 13$ & -40.1 & 33 & $27 / 11$ \\
\hline \multirow[t]{2}{*}{$\mathbf{T}$} & 1 - Lysozyme & P61626 & $17 / 14$ & -15.6 & 21 & $5 / 4$ \\
\hline & 2 - Fatty acid-binding protein & P05413 & $15 / 14$ & -13.6 & 30 & $7 / 4$ \\
\hline \multirow[t]{2}{*}{$\mathbf{U}$} & 1 - Lysozyme & P61626 & $17 / 13$ & -31.0 & 34 & $11 / 10$ \\
\hline & 2 - Fatty acid-binding protein & P05413 & $15 / 13$ & -6.6 & 12 & $3 / 2$ \\
\hline $\mathbf{v}$ & $\alpha$-Lactalbumin & P00709 & $16 / 10$ & -5.8 & 11 & $3 / 2$ \\
\hline
\end{tabular}

differences between the two pasteurization methods. MFG membrane proteins have an important physiological effect, as they may contribute to protection against bacteria and viruses in the gastrointestinal tract of newborn infants. Different clinical trials have also indicated that MFGPs have potential beneficial effects on the immune system and on the cognitive functions of newborn children (Demmelmair, Prell, Timby, \& Lönnerdal, 2017). The protein profile of MFGPs was changed to a great extent by the thermal processing, albeit with less alteration of the
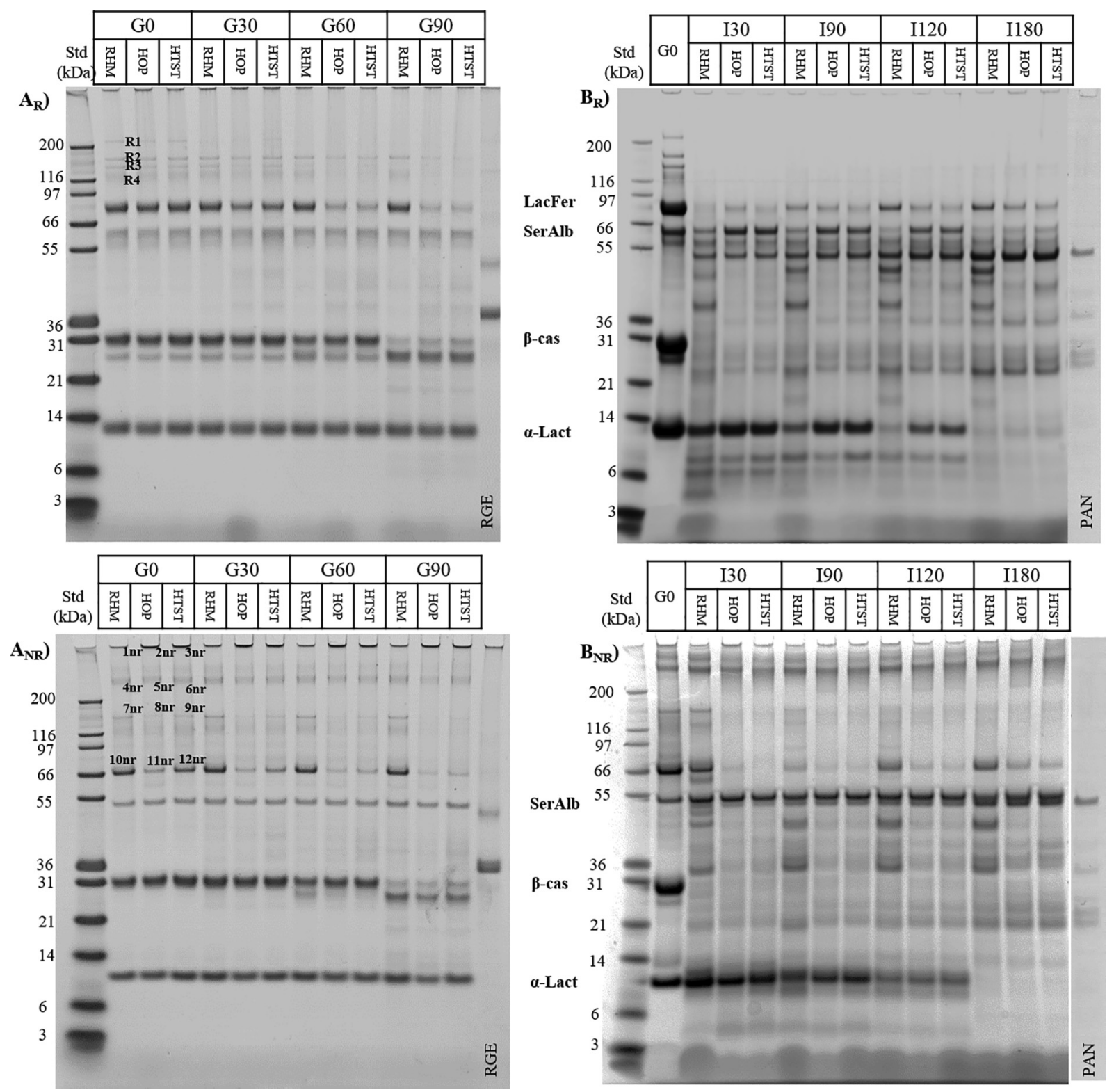

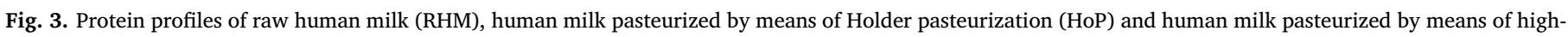

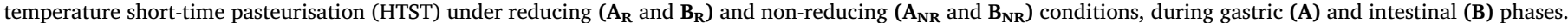

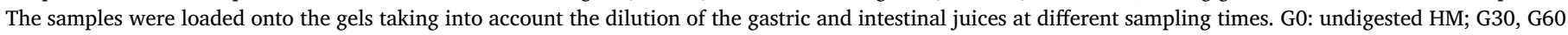

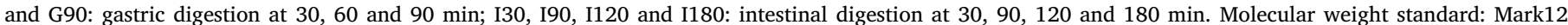

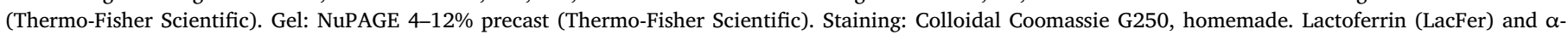

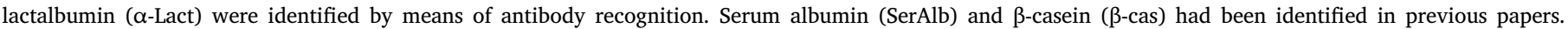
Differently coded protein bands were identified by means of LC-MS/MS (see Table 1). 

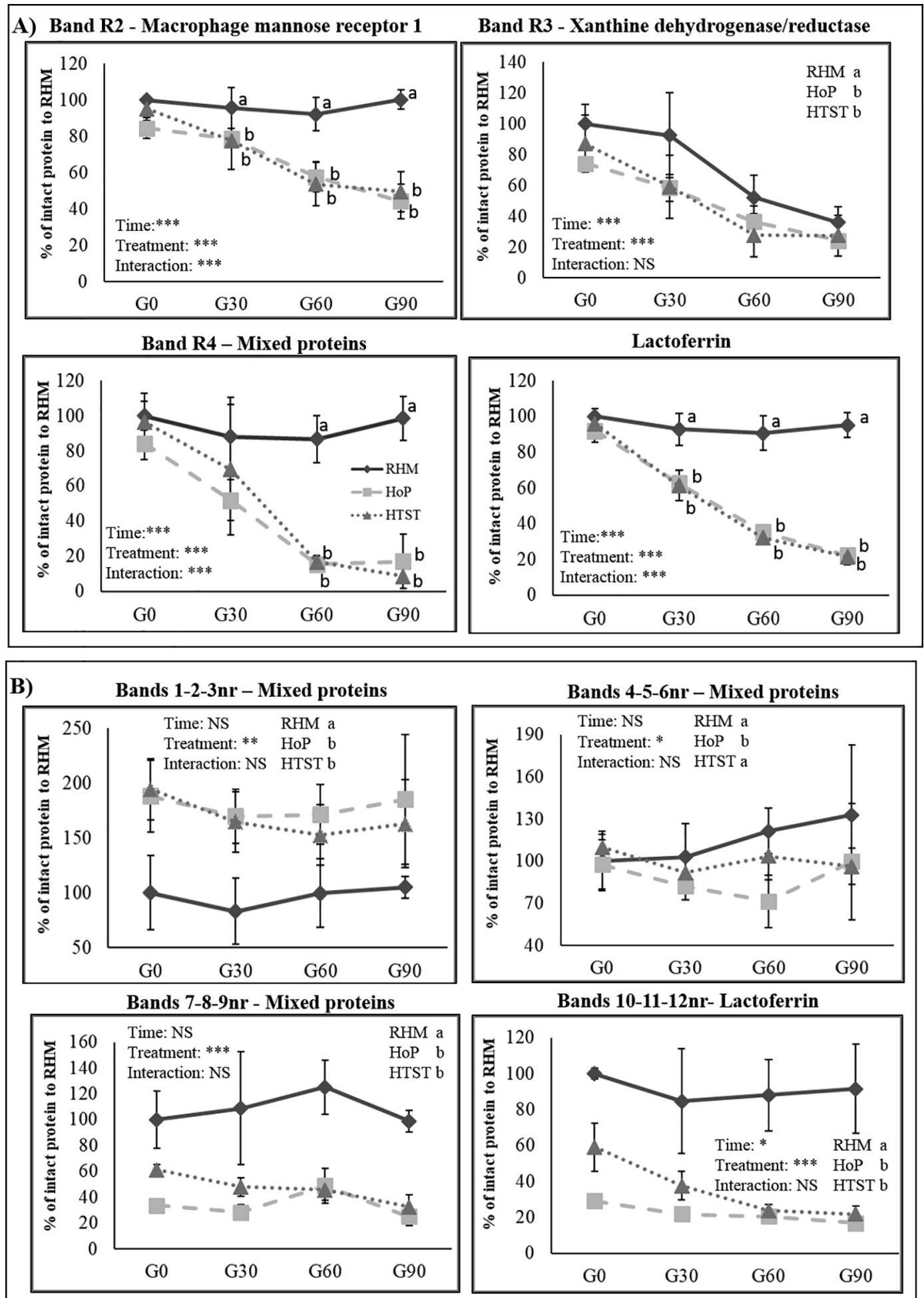

Fig. 4. Percentage of intact band (as the relative abundance to the undigested raw human milk band) for bands showing a significant difference between raw and pasteurized HM samples during gastric digestion, as obtained by means of densitometric analysis of the gels under reducing (A) and non-reducing (B) conditions. The data represent means \pm standard deviations $(n=3)$. Statistics: two-way ANOVA at $p<0.001(* * *) ; p<0.01(* *) ; p<0.05(*) ; p>0.05$ (NS). Tukey's (homogeneous variance) or Dunn's (heterogeneous variance) post hoc tests were performed. Letters indicate different classes when interaction factor was significantly different.

native MFGP profile in the HTST milk than in the HoP. Particularly, native lactoferrin was still present at the surface of the fat globule of HTST milk unlike that in HoP milk, where the band intensity was faint. A clear involvement of lactoferrin, xanthine dehydrogenase and BSSL was observed in the formation of aggregates, which were more abundant for the HoP milk. The fatty acid-binding protein and $\alpha$-lactalbumin were only detected in the MFGP fraction after pasteurization, as already described (Ma et al., 2019). The conformational rearrangements after pasteurization also seemed to affect lysozyme and $\beta$-casein. 


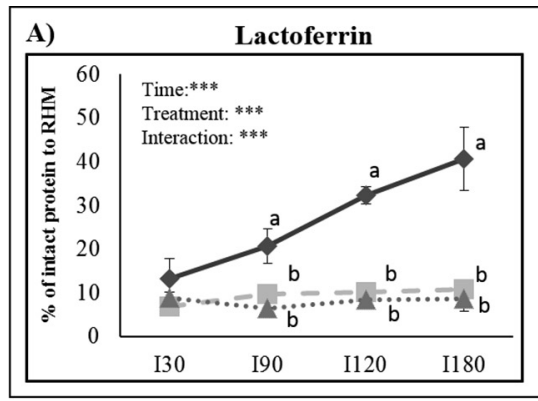

B) Bands 4-5-6nr - Mixed proteins

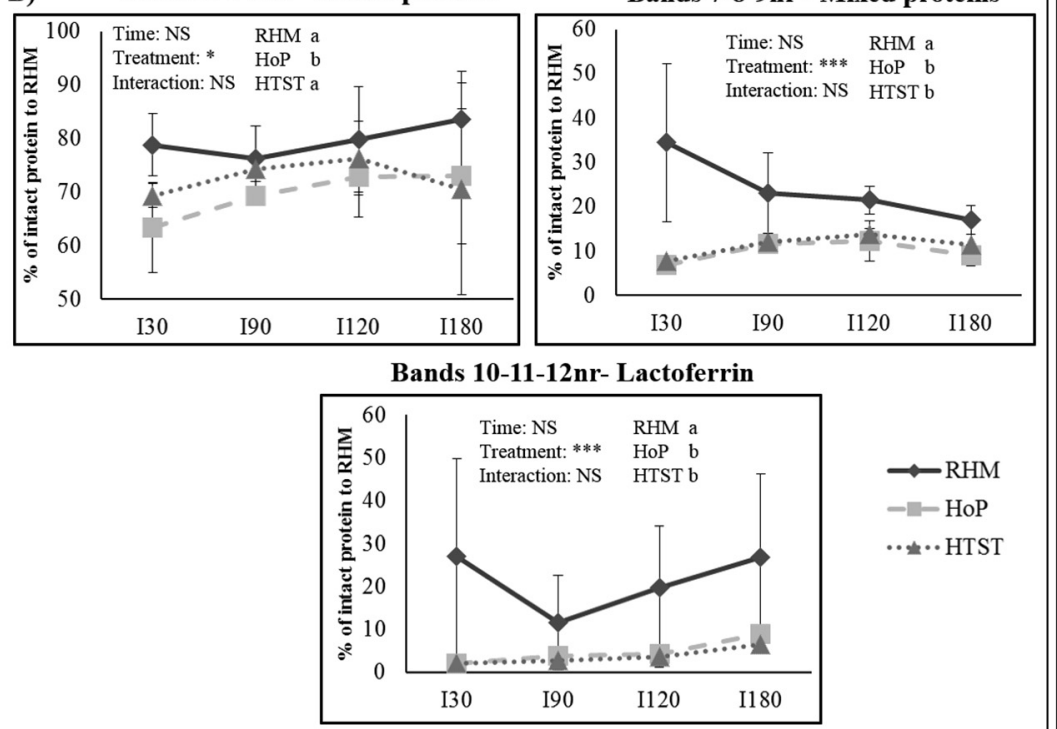

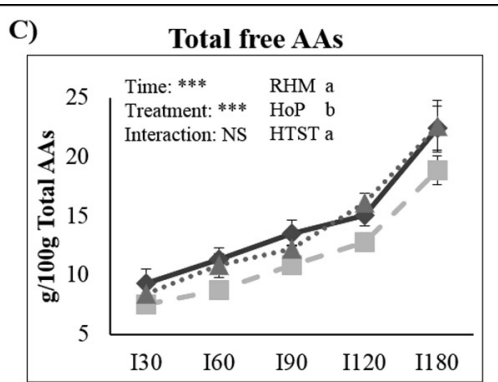

Non essential free AAs

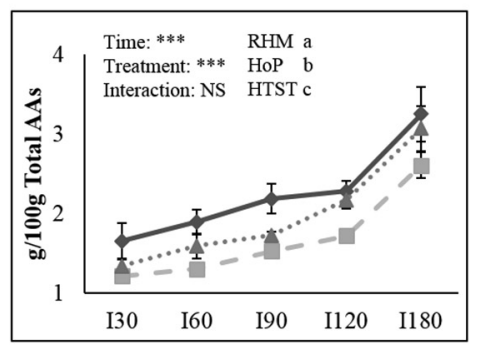

Essential free AAs

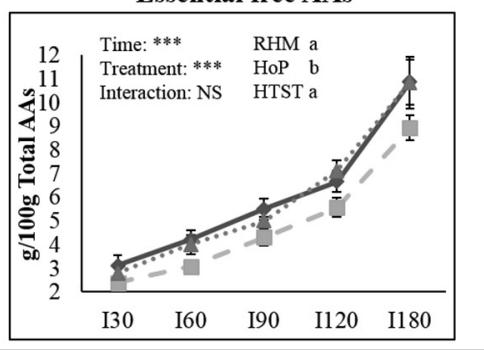

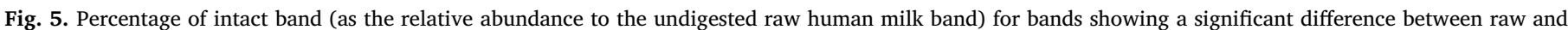

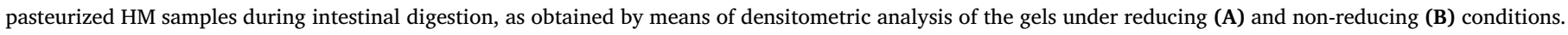

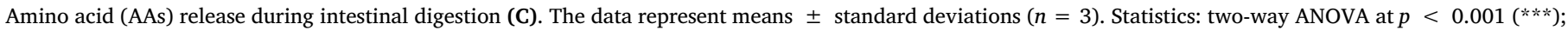

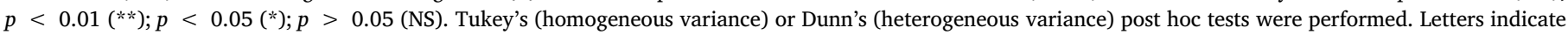
different classes when interaction factor was significantly different.

\subsection{Particle destabilization during gastric digestion}

A strong particle destabilization was detected in the RHM after 60 min of gastric digestion, with the formation of larger aggregates, while neither of the pasteurized milks showed a similar particle size shift. The emulsion destabilization observed in this study for RHM was in agreement with previous studies, conducted both in vitro (De Oliveira, Bourlieu, et al., 2016; De Oliveira, Deglaire, et al., 2016) and in vivo (de Oliveira et al., 2017). The lack of formation of large gastric aggregates in the HoP-treated HM had previously been shown to not interfere with gastric emptying in preterm neonates (de Oliveira et al., 2017), a factor previously considered as an indicator of the development of feeding intolerance and of necrotizing enterocolitis in preterm newborn infants (Li et al., 2014).

\subsection{Kinetics of proteolysis}

Despite the significant differences in the protein pattern of the undigested HM in the three samples, the proteolysis profiles of both pasteurized HM were similar, and differences with respect to RHM were observed. The only significant difference between the two pasteurization methods was a slightly higher resistance to digestion of one band containing immunoglobulins and lactoferrin in RHM and in HTST, with respect to HoP, although its extent was limited. Immunoglobulins, which are bioactive proteins, are known to persist throughout digestion, and to be found in the stool of breastfed infants (Lönnerdal, 2016). Since densitometric analysis of the protein bands on gels suffer from limitations for faint bands, caution should be taken when considering quantitative data. Thus, further confirmation could be achieved by directly targeting IgAs in the stool of infants fed RHM, HoP or HTST.

Both pasteurization procedures had, on the other side, a major impact on lactoferrin structure, and resulted in increased proteolysis, compared to RHM. Lactoferrin facilitates the first step of the iron absorption process, and stimulates epithelial cell proliferation and differentiation (Lönnerdal, 2016). Its faster hydrolysis and higher aggregation, following all pasteurization techniques, may thus be detrimental to the overall protective effect on preterm newborn infants, although its main siderophore activity could be preserved when aggregated, and this aspect warrants further functional investigations. On the other hand, lactoferrin is a recognized source of bioactive peptides, which plays an important antimicrobial role in the gastrointestinal tract (Wada \& Lönnerdal, 2014), and its increased digestibility, following pasteurization, may therefore be beneficial. Peptidomic analysis, which is currently underway, may shed light on this peculiar aspect.

Despite the minor differences observed at the protein level during intestinal proteolysis within HoP and HTST milk, a significant difference was found in the total and essential free AA released during digestion. A significantly lower amount of both was found in the HoP digests, that is, up to $-20 \%$ with respect to the HTST. The impact of pasteurization on AA release during digestion has not been exhaustively investigated in preterm models so far (de Oliveira et al., 2016), and never regarding HTST milk. The higher release of both total and essential AAs in the intestinal tract found in the RHM and HTST samples could be a positive factor for the physiological state of preterm infants, 
since they represent an important source of energy and fuel lymphocyte differentiation, and they contribute to intestinal cell integrity and to protection against oxidative stress (Valentine et al., 2010). Since this differential release of AAs between HoP and HTST does not correspond to the protein degradation pattern, further peptidomic investigation could contribute to a better understanding of the fate of proteins during digestion.

\subsection{Kinetics of lipolysis}

No impact of pasteurization on the lipid hydrolysis kinetics has been found in the present study, although we did observe a high level of prelipolysis in the undigested milk, probably related to the length of storage in the HMB before the thermal treatments, or to the freezingthawing cycle before pooling and analysis. Our results have confirmed previous observations on preterm milk lipolysis by De Oliveira, Bourlieu, et al. (2016). Since lipids are an important source of energy for newborn infants, are involved in the regulation of the immune system, and are converted to metabolites that regulate inflammatory processes and organogenesis, a low impact of pasteurization on their physiological release is important. Clinical evidence suggests that alterations in FA intake in preterm infants may have implications on the risk of chronic lung disease, necrotizing enterocolitis, retinopathy and neurodevelopment (Robinson \& Martin, 2017). Within this framework, the reduced abundance and activity (data not shown) of BSSL, following both pasteurization methods, seemed to have little or no impact on the total degradation of the TAGs, its function having been balanced by the endogenous intestinal lipases.

\section{Conclusion}

The use of an in vitro dynamic digestion model has allowed us to unravel the differential impact of HTST pasteurization on the digestive kinetics of proteins and lipids in donated HM, thus providing an alternative to the available costly and controversial in vivo tests, especially when dealing with vulnerable infants, such as preterm infants. HTST pasteurization, performed using specific equipment validated for the processing of donor HM, has been confirmed to be less damaging on the undigested human milk than the standard HoP, particularly regarding bioactive proteins, such as lactoferrin, immunoglobulins and milk fat globule associated proteins. The present study has proved for the first time that the HTST technique led to similar proteolytic patterns to those resulting from HoP, when observed at the protein level. Some differential behavior was observed between HTST and HOP, including a slightly higher retention of immunoglobulins and lactoferrin, and a higher intestinal release of total and essential free amino acids after HTST. The overall impact of such differences warrants further in vivo investigation. An ongoing peptidomic analysis is also expected to provide more insight into the differential effect of the two pasteurization methods on the digestion fate of HM proteins in preterm infants.

\section{Funding}

SN was supported by the French Government [Campus France Italie grant number $895240 \mathrm{k}]$.

\section{CRediT authorship contribution statement}

Stefano Nebbia: Investigation, Methodology, Writing - original draft. Marzia Giribaldi: Conceptualization, Data curation, Writing review \& editing. Laura Cavallarin: Conceptualization, Supervision, Project administration, Writing - review \& editing. Enrico Bertino: Resources, Methodology. Alessandra Coscia: Resources, Methodology. Valérie Briard-Bion: Investigation. Jordane Ossemond: Investigation. Gwénaële Henry: Investigation. Olivia Ménard: Investigation, Supervision. Didier Dupont: Supervision, Funding acquisition. Amélie Deglaire: Conceptualization, Supervision, Methodology, Data curation, Writing - review \& editing.

\section{Declaration of Competing Interest}

The authors declare the following financial interests/personal relationships which may be considered as potential competing interests: MG, LC, EB and AC have competing interests, since they are the inventors of a patent pertaining to the HTST human milk pasteurizer used in the study (Patent no. EP2974603 A1). No conflict of interest exists for the remaining authors.

\section{Acknowledgments}

The authors would like to thank Fredéric Carrière and GERME S.A. for providing the RGE.

\section{Appendix A. Supplementary data}

Supplementary data to this article can be found online at https:// doi.org/10.1016/j.foodchem.2020.127126.

\section{References}

Barello, C., Garoffo, L. P., Montorfano, G., Zava, S., Berra, B., Conti, A., et al. (2008). Analysis of major proteins and fat fractions associated with mare's milk fat globules. Molecular Nutrition and Food Research, 52(12), 1448-1456. https://doi.org/10.1002/ mnfr.200700311.

Baro, C., Giribaldi, M., Arslanoglu, S., Giuffrida, M. G., Dellavalle, G., Conti, A., et al. (2011). Effect of two pasteurization methods on the protein content of human milk. Frontiers in Bioscience (Elite Edition), 3, 818-829.

Berry, D. A., \& Ayers, G. D. (2006). Symmetrized percent change for treatment comparisons. The American Statistician, 60(1), 27-31. https://doi.org/10.1198/ 000313006 X0684 T.

Billard, H., Simon, L., Desnots, E., Sochard, A., Boscher, C., Riaublanc, A., et al. (2016). Calibration Adjustment of the Mid-infrared Analyzer for an Accurate Determination of the Macronutrient Composition of Human Milk. Journal of Human Lactation, 32(3), NP19-NP27. https://doi.org/10.1177/0890334415588513.

Bourlieu, C., Bouzerzour, K., Ferret-Bernard, S., Bourgot, C. L., Chever, S., Ménard, O., et al. (2015). Infant formula interface and fat source impact on neonatal digestion and gut microbiota: Infant formula structure affects neonatal health. European Journal of Lipid Science and Technology, 117(10), 1500-1512. https://doi.org/10.1002/ejlt. 201500025.

Bourlieu, C., Ménard, O., Bouzerzour, K., Mandalari, G., Macierzanka, A., Mackie, A. R. et al. (2014). Specificity of infant digestive conditions: Some clues for developing relevant in vitro models. Critical Reviews in Food Science and Nutrition, 54(11), 1427-1457. https://doi.org/10.1080/10408398.2011.640757.

Candiano, G., Bruschi, M., Musante, L., Santucci, L., Ghiggeri, G. M., Carnemolla, B., et al. (2004). Blue silver: A very sensitive colloidal Coomassie G-250 staining for proteome analysis. Electrophoresis, 25, 1327-1333. https://doi.org/10.1002/elps.200305844.

de Oliveira, S. C., Bellanger, A., Ménard, O., Pladys, P., Le Gouar, Y., Dirson, E., et al. (2017). Impact of human milk pasteurization on gastric digestion in preterm infants: A randomized controlled trial. The American Journal of Clinical Nutrition, 105(2), 379-390. https://doi.org/10.3945/ajcn.116.142539.

de Oliveira, S. C., Bourlieu, C., Ménard, O., Bellanger, A., Henry, G., Rousseau, F., et al. (2016). Impact of pasteurization of human milk on preterm newborn in vitro digestion: Gastrointestinal disintegration, lipolysis and proteolysis. Food Chemistry, 211, 171-179. https://doi.org/10.1016/j.foodchem.2016.05.028.

de Oliveira, S. C., Deglaire, A., Ménard, O., Bellanger, A., Rousseau, F., Henry, G., et al. (2016). Holder pasteurization impacts the proteolysis, lipolysis and disintegration of human milk under in vitro dynamic term newborn digestion. Food Research International, 88, 263-275. https://doi.org/10.1016/j.foodres.2015.11.022.

Deglaire, A., Oliveira, S. D., Jardin, J., Briard-Bion, V., Kroell, F., Emily, M., et al. (2019). Impact of human milk pasteurization on the kinetics of peptide release during in vitro dynamic digestion at the preterm newborn stage. Food Chemistry, 281, 294-303. https://doi.org/10.1016/j.foodchem.2018.12.086.

Demmelmair, H., Prell, C., Timby, N., \& Lönnerdal, B. (2017). Benefits of lactoferrin, osteopontin and milk fat globule membranes for infants. Nutrients, 9(8), 817. https:// doi.org/10.3390/nu9080817.

Dhar, J., Fichtali, J., Skura, B. J., Nakai, S., \& Davidson, A. G. F. (1996). Pasteurization efficiency of a HTST system for human milk. Journal of Food Science, 61(3), 569-573. https://doi.org/10.1111/j.1365-2621.1996.tb13160.x.

Donalisio, M., Rittà, M., Francese, R., Civra, A., Tonetto, P., Coscia, A., et al. (2018). High temperature-short time pasteurization has a lower impact on the antiviral properties of human milk than holder pasteurization. Frontiers in Pediatrics, 6, 304. https:// doi.org/10.3389/fped.2018.00304.

Escuder-Vieco, D., Espinosa-Martos, I., Rodríguez, J. M., Corzo, N., Montilla, A., Siegfried, P., et al. (2018). High-temperature short-time pasteurization system for donor milk in 
a human milk bank setting. Frontiers in Microbiology, 9, 926. https://doi.org/10. 3389/fmicb.2018.00926.

Escuder-Vieco, D., Espinosa-Martos, I., Rodríguez, J. M., Fernández, L., \& Pallás-Alonso, C. R. (2018). Effect of HTST and Holder pasteurization on the concentration of immunoglobulins, growth factors, and hormones in donor human milk. Frontiers in Immunology, 9, 2222. https://doi.org/10.3389/fimmu.2018.02222.

Giribaldi, M., Coscia, A., Peila, C., Antoniazzi, S., Lamberti, C., Ortoffi, M., et al. (2016). Pasteurization of human milk by a benchtop High-Temperature Short-Time device. Innovative Food Science and Emerging Technologies, 36, 228-233. https://doi.org/10. 1016/j.ifset.2016.07.004.

Goldblum, R. M., Dill, C. W., Albrecht, T. B., Alford, E. S., Garza, C., \& Goldman, A. S. (1984). Rapid high-temperature treatment of human milk. The Journal of Pediatrics, 104(3), 380-385. https://doi.org/10.1016/S0022-3476(84)81099-9.

Hammer, O., Harper, D. A. T., \& Ryan, P. D. (2001). PAST: Paleontological Statistics Software Package for Education and. Data Analysis, 9.

Hamprecht, K., Maschmann, J., Müller, D., Dietz, K., Besenthal, I., Goelz, R., et al. (2004). Cytomegalovirus (CMV) Inactivation in Breast Milk: Reassessment of Pasteurization and Freeze-Thawing. Pediatric Research, 56(4), 529-535. https://doi.org/10.1203/ 01.PDR.0000139483.35087.BE.

Li, Y.-F., Lin, H.-C., Torrazza, R. M., Parker, L., Talaga, E., \& Neu, J. (2014). Gastric residual evaluation in preterm neonates: A useful monitoring technique or a hin drance? Pediatrics and Neonatology, 55(5), 335-340. https://doi.org/10.1016/j. pedneo.2014.02.008.

Lönnerdal, B. (2016). Bioactive proteins in human milk: Health, nutrition, and implications for infant formulas. The Journal of Pediatrics, 173, S4-S9. https://doi.org/10. 1016/j.jpeds.2016.02.070.

Ma, Y., Zhang, L., Wu, Y., \& Zhou, P. (2019). Changes in milk fat globule membrane proteome after pasteurization in human, bovine and caprine species. Food Chemistry, 279, 209-215. https://doi.org/10.1016/j.foodchem.2018.12.015.

Mayayo, C., Montserrat, M., Ramos, S. J., Martínez-Lorenzo, M. J., Calvo, M., Sánchez, L., et al. (2016). Effect of high pressure and heat treatments on IgA immunoreactivity and lysozyme activity in human milk. European Food Research and Technology, 242(6), 891-898. https://doi.org/10.1007/s00217-015-2595-7.

Meier, P., Patel, A., \& Esquerra-Zwiers, A. (2017). Donor Human Milk Update: Evidence, Mechanisms, and Priorities for Research and Practice. The Journal of Pediatrics, 180, 15-21. https://doi.org/10.1016/j.jpeds.2016.09.027.
Ménard, O., Cattenoz, T., Guillemin, H., Souchon, I., Deglaire, A., Dupont, D., et al. (2014). Validation of a new in vitro dynamic system to simulate infant digestion. Food Chemistry, 145, 1039-1045. https://doi.org/10.1016/j.foodchem.2013.09.036.

Moro, G. E., Billeaud, C., Rachel, B., Calvo, J., Cavallarin, L., Christen, L., et al. (2019). Processing of Donor Human Milk: Update and Recommendations From the European Milk Bank Association (EMBA). Frontiers in Pediatrics, 7, 49. https://doi.org/10.3389/ fped.2019.00049.

Peila, C., Emmerik, N. E., Giribaldi, M., Stahl, B., Ruitenberg, J. E., van Elburg, R. M., et al. (2017). Human Milk Processing: A Systematic Review of Innovative Techniques to Ensure the Safety and Quality of Donor Milk. Journal of Pediatric Gastroenterology and Nutrition, 64(3), 353-361. https://doi.org/10.1097/MPG.0000000000001435.

Peila, C., Moro, G., Bertino, E., Cavallarin, L., Giribaldi, M., Giuliani, F., et al. (2016). The Effect of Holder Pasteurization on Nutrients and Biologically-Active Components in Donor Human Milk: A Review. Nutrients, 8(8), 477. https://doi.org/10.3390/ nu8080477.

Robinson, D. T., \& Martin, C. R. (2017). Fatty acid requirements for the preterm infant Seminars in Fetal and Neonatal Medicine, 22(1), 8-14. https://doi.org/10.1016/j.siny. 2016.08.009.

Valentine, C. J., Morrow, G., Fernandez, S., Gulati, P., Bartholomew, D., Long, D., et al. (2010). Docosahexaenoic acid and amino acid contents in pasteurized donor milk are low for preterm infants. The Journal of Pediatrics, 157(6), 906-910. https://doi.org/ 10.1016/j.jpeds.2010.06.017.

Villamor-Martínez, E., Pierro, M., Cavallaro, G., Mosca, F., Kramer, B., \& Villamor, E. (2018). Donor human milk protects against bronchopulmonary dysplasia: A systematic review and meta-analysis. Nutrients, 10(2), 238. https://doi.org/10.3390/ nu10020238.

Wada, Y., \& Lönnerdal, B. (2014). Bioactive peptides derived from human milk proteins-Mechanisms of action. The Journal of Nutritional Biochemistry, 25(5), 503-514. https://doi.org/10.1016/j.jnutbio.2013.10.012.

Wessel, D., \& Flügge, U. I. (1984). A method for the quantitative recovery of protein in dilute solution in the presence of detergents and lipids. Analytical Biochemistry, 138(1), 141-143. https://doi.org/10.1016/0003-2697(84)90782-6.

Ye, A., Singh, H., Taylor, M. W., \& Anema, S. (2004). Interactions of whey proteins with milk fat globule membrane proteins during heat treatment of whole milk. Le Lait, 84(3), 269-283. https://doi.org/10.1051/lait:2004004. 